\title{
RESPONSABILIDADE SOCIAL NO CONTEXTO DE DESENVOLVIMENTO LOCAL: UT estudo no Arranjo Produtivo Local de Equipamentos Médicos e Hospitalares de Ribeirão Preto - SP
}

\author{
C. N. CULTRI \\ Universidade Federal de São Carlos \\ milacultri@gmail.com
}

Submetido 26/02/2020 - Aceito 29/04/2020

DOI: $10.15628 /$ holos.2020.9532

\section{RESUMO}

O artigo teve o objetivo de apresentar a importância da Responsabilidade Social (RS) para desenvolvimento em um Arranjo Produtivo Local (APL), no interior do Estado de São Paulo. Foi realizada uma revisão bibliográfica e um estudo de caso. Buscou-se eleger dois dos principais padrões de gestão de responsabilidade social publicados até o momento. Em âmbito internacional, a norma ISO 26000 publicada em 2010 pela International Standart Organization (ISO) e no âmbito nacional, a norma brasileira ABNT NBR 16001 de 2004 pela Associação Brasileira de Normas Técnicas (ABNT), ambas importantíssimas no que tange aos indicadores sociais e ao público-alvo que se relacionam com as organizações.
Pelas vias da pesquisa exploratória, foram extraídos dados socioeconômicos sobre o segmento de fabricantes de equipamentos médicos, odontológicos e hospitalares. As análises apontam para a oportunidade das empresas e organizações inserirem nos seus planejamentos alguns indicadores sociais de instituições como Instituto Ethos, do Instituto Brasileiro de Análises Socioeconômicas, da Global Report Initiative e da Organização das Nações Unidas. Conclui-se que articulando ações de responsabilidade social é possível agregar valor para as propostas de políticas públicas de desenvolvimento territorial na região do APL.

PALAVRAS-CHAVE: Arranjo produtivo local, políticas públicas, responsabilidade social, desenvolvimento regional.

\section{SOCIAL RESPONSIBILITY IN THE LOCAL DEVELOPMENT CONTEXT: a study in the Local Productive Arrangement of Medical and Hospital Equipment in Ribeirão Preto - SP}

\begin{abstract}
The purpose of this article was to present the importance of Social Responsibility (SR) for development in a Local Productive Arrangement (cluster), in the interior of the State of São Paulo. Carried out a bibliographic review and a case study. Sought to elect two of the main standards of social responsibility management published so far. At the international level, the ISO 26000 standard published in 2010 and at the national level, the Brazilian standard ABNT NBR 16001 of 2004, both of which are very important with regard to social indicators and the target audience that relate to organizations. Through
\end{abstract}

exploratory research, socioeconomic data on the segment of manufacturers of medical, dental and hospital equipment were extracted. The analyzes point to the opportunity for companies and organizations to include in their planning some social indicators and tools from institutions such as Instituto Ethos, the Brazilian Institute of Socioeconomic Analysis, the Global Report Initiative and the United Nations. Concluded that by articulating social responsibility actions, it is possible to present value for public policy proposals for territorial development in the APL region.

KEYWORDS: Local productive arrangement, public policies, social responsibility, regional development. 


\section{INTRODUÇÃO}

No Brasil, os indicadores sociais vem ganhando importância política e acadêmica, como se pode evidenciar no aumento de artigos e periódicos com esta temática. Aos poucos vão se tornando cada vez mais populares devido a possibilidade de representar os fatores relativos ao desenvolvimento regional, conforme se pode observar nas publicações crescentes das bases de dados que apresentam dados nacionais, tais como o Portal de Periódicos da CAPES, plataforma Web of Science e Scopus, e nas instituições como Associação Brasileira de Normas Técnicas (ABNT), Instituto Nacional de Metrologia, Normalização e Qualidade Industrial (INMETRO) entre outras.

Países desenvolvidos já utilizam bases de dados e controles para se mensurar os aspectos sociais. Por exemplo, na França já se utiliza os indicadores sociais da norma ISO 26000 organizada pela International Standart Organization (ISO). As autoridades francesas têm preconizado o uso de indicadores deste tipo para se analisar a qualidade do desenvolvimento local. Tal que um dos índices de Desenvolvimento Humano (IDH) mais elevados do mundo é o da França (Francisco, 2020).

Além das organizações citadas, outras como o Instituto Ethos, o Instituto Brasileiro de Análises Socioeconômicas, a Global Report Initiative e a Organização das Nações Unidas também trabalham na divulgação de publicações como relatórios de sustentabilidade, balanços sociais e indicadores ambientais, sociais e econômicos muito pertinentes para o desenvolvimento local e regional. São documentos que divulgam ações de organizações dos mais variados segmentos. Algumas instituições encontraram incentivos e políticas públicas para desenvolverem novos modelos de gestão e inovação.

Para contextualizar a importância da responsabilidade social a nível mundial, observamos incentivos tal como a 21a Conferência das Partes - COP 21 (ocorrida em 2015) que nos faz perceber a importância de ações sustentáveis, pois colocou em pauta a necessidade de refletirmos sobre o desenvolvimento local. Outra instituição relevante neste contexto é a United Nations Environment Programme (UNEP), com vários Programa das Nações Unidas para o Meio Ambiente. Há várias décadas, a UNEP (2009) ressalva que empreendimentos sustentáveis podem dar uma contribuição significativa para à redução da pobreza e para a sustentabilidade ambiental. Segundo eles, estas iniciativas de negócios melhoram as atividades humanas ao mesmo tempo em que viabilizam o bem-estar e o uso dos recursos naturais.

Em nossa breve revisão e análise da literatura a respeito da temática "Responsabilidade Social" e suas características, destacamos autores envolvidos com a temática há décadas: Tachizawa (2002), Ashley (2003), Cajazeira \& Barbieri (2006), Singer (2002) e Cultri; Saavedra \& Ometto (2010). Além destes, instituições de alta relevância como International Standart Organization (ISO), United Nations Environment Programme (UNEP), Instituto Nacional de Metrologia, Normalização e Qualidade Industrial (INMETRO), Associação Brasileira de Normas Técnicas (ABNT) e Instituto ETHOS de responsabilidade social. Para contextualizar as noções de "Desenvolvimento Local" destaque para experiência de Silveira \& Bocayuva (1999), Frey (2003), Joyal (2004), Rossini \& Martinelli (2007) e Aguilera Urquiza \& Maciel (2019). 
Dois marcos relevantes sobre responsabilidade social estão pautadas nas vias da norma internacional ISO 26000, publicada em 2010, pela International Standart Organization (ISO) e na norma brasileira ABNT NBR 16001 de 2004, organizada pela Associação Brasileira de Normas Técnicas (ABNT). Ambas importantíssimas no que tange aos indicadores sociais e ao público-alvo que se relacionam com as organizações, por isto elas serão tratadas com mais detalhes neste estudo.

Desta forma, na primeira parte deste estudo, apresentaremos algumas referências e reflexões extraídas das leituras bibliográficas e dos documentos oficiais. Na sequência, a construção do estudo de caso com observações in locu e pesquisa de exploratória para fornecimento do constructo de uma realidade brasileira. Ainda para enriquecer os nossos questionamentos e argumentos, realizamos um levantamento buscando sites das empresas e organizações com alto impacto na localidade de Ribeirão Preto, tais como Serviço Brasileiro de Apoio às Micros e Pequenas Empresas (SEBRAE), Supera Incubadora - Unidade Campus USP (SUPERA), Fundação Instituto Pólo Avançado da Saúde (FIPASE), prefeitura entre outras que compõem o Arranjo Produtivo Local de Equipamentos Médicos e Hospitalares de Ribeirão Preto - SP. Visto sua relevância de grande impacto local e internacional no que tange a área de tecnologia e saúde.

\section{REVISÃO DA LITERATURA}

2.1 Dinâmicas de inovação social: a norma internacional ISO 26000 e brasileira ABNT NBR 16001 de responsabilidade social

Entendemos que a qualidade de vida de uma sociedade vai além dos aspectos econômicos e do poder de compra dos indivíduos, ela perpassa pela vida coletiva e pela satisfação de viver em cada localidade. Aguilera Urquiza e Maciel (2019, p. 1217) apontam para a oportunidade de uma ideia de "Desenvolvimento Local que fomente um tecido social participativo e autônomo diante dos desafios do mundo contemporâneo". Assim, ao despertar-se para a relevância da sustentabilidade entra em cena um novo modelo que valoriza as pessoas e o seu ambiente, e que valoriza políticas públicas de desenvolvimento territorial (Rodrigues e Santos, 2018; Correia et. al, 2017).

O Plano da União Europeia para a Economia Circular e o Acordo de Paris de 2015, ambos publicados na 21 a - Conferência das Partes (COP 21), trouxeram mais incentivos e políticas revigorando os aspectos para o desenvolvimento sustentável. Tal desenvolvimento se efetiva com diretrizes, políticas e ações de responsabilidade social, ambiental e econômica. Para Oliveira et. at. (2019), a partir de 2015 tornaram-se mais evidentes as necessidades de se expandir e se solidificar ações voltadas aos ideais de desenvolvimento sustentável.

A difusão da responsabilidade entre os cidadãos ganha ênfase nesse novo cenário. No atual momento, com inferências de pandemias globais, o Estado "sozinho" já não é o único responsável pelo bom convívio social. No Brasil, por exemplo, existe uma grande demanda sob os serviços do setor público, em alguns deles como na área da saúde, existe uma sobrecarga que já levou ou poderá muito em breve levar o sistema público ao colapso. Deixando de atender a população carente, haja vista, que grande parte desse setor não conseguiu responder as expectativas da 
população brasileira nas últimas décadas. Por isto se torna importante que a responsabilidade social seja praticada por todos numa sociedade, incluindo empresas e organizações públicas.

Nas cidades, particularmente nos países em desenvolvimento, observa-se uma crescente perda de governabilidade. Faltam condições e ferramentas adequadas de gestão para implementar iniciativas efetivas de desenvolvimento local, capazes de promover um desenvolvimento sustentável no âmbito das comunidades locais, respeitando as exigências de justiça social. Faltam estruturas e instituições de governança local apropriadas para estimular a ação coletiva e articular os diferentes atores locais em torno de objetivos comuns de desenvolvimento local (Frey, 2003, p.165).

Sob este prisma de grandes transformações é evidente o envolvimento da população e dos agentes econômicos privados nas decisões políticas e caráter público no que tange aos interesses da sociedade. Entre a superação dos desafios impostos pela carência de serviços e o papel das empresas inovadoras, que além da função de industrializar produtos também cumprem o exercício de praticar a responsabilidade empresarial. Na nossa perspectiva acrescentamos que os consumidores também tem papel importante para exigir "mais" responsabilidade das empresas, podendo valorizar inovações e sustentabilidade. Por tudo isto se faz relevante a Responsabilidade Social.

A noção de responsabilidade social das empresas surgiu no final do século XIX, nos Estados Unidos da América com a publicação do livro "O Evangelho da Riqueza" de Andrew Carnegie, escrito em 1889. Este documento apresentou dois princípios básicos para à Responsabilidade Corporativa sendo eles, o princípio da caridade e o princípio do zelo. Após 1953, o conceito se popularizou com o livro "Responsabilidade Social do Homem de Negócios", cujo autor Howard R. Bowen ficou conhecido como o pai da responsabilidade social.

No Brasil, crescente tem sido a utilização do conceito de responsabilidade social nas organizações. Essa denominação diz respeito a uma nova realidade empresarial que visa assegurar competitividade implementando ações de cunho social para adequar-se aos padrões culturais, éticos e de valores das comunidades internacionais, com as quais mantém relações comerciais.

De acordo com o Instituto Ethos, a responsabilidade social é focada na cadeia de negócios da empresa e engloba preocupações com um público maior (acionistas, funcionários, prestadores de serviço, fornecedores, consumidores, comunidade, governo e meio ambiente), cuja demanda e necessidade da empresa deve buscar entender e incorporar aos negócios. Por definição, responsabilidade social é

[...] o compromisso que uma organização deve ter para com a comunidade, expresso por meio de atos a atitudes que a afetem positivamente, de modo amplo, ou a alguma comunidade, de modo específico agindo proativamente e coerentemente no que tange ao seu papel específico na sociedade e sua prestação de contas para com ela (Aslhey et. al. 2003, p. 06).

Tachizawa (2005) observa que o conceito deve expressar compromisso com adoção e difusão de valores, conduta e procedimentos que induzam e estimulem o contínuo aperfeiçoamento dos processos empresariais, para que também resultem em preservação e melhoria da qualidade de vida da sociedade do ponto de vista ético, social e ambiental. 
Ao exercício de Responsabilidade Social está inserido fortemente o compromisso ético empresarial compreendido entre os princípios e padrões que orientam o comportamento no mundo dos negócios, incluindo o controle de poluição, a utilização de mão-de-obra infantil, discriminação racial e salarial, envolvimento em corrupção, transparência nos negócios (Barbosa et. al., 2002).

A norma internacional "ISO 26000 - Diretrizes sobre Responsabilidade Social", foi lançada no dia 1 o de novembro de 2010, em Genebra, na Suíça. A iniciativa de organizar o conteúdo ficou com a cargo da International Organization for Standardization (ISO), formada por membros de 99 países. Este comitê reuniu assuntos emergentes, que tangem carências ou necessidades sociais.

Neste cenário, o Brasil já possuía experiência deste 2004 por ser o primeiro país a lançar uma norma de responsabilidade social. A expertise brasileira consolidada na implantação da norma NBR 16001 - Sistema da Gestão da Responsabilidade Social (SGRS) contribuiu para a comissão internacional da ISO, tanto que o gestor do comitê de RS foi presidido pelo brasileiro Jorge Cajazeira. A norma brasileira foi publicada em 2004 pela Associação Brasileira de Normas Técnicas (ABNT) com temas eleitos como relevantes para a sociedade brasileira e com características de um sistema de gestão proposto para ser sistematizados e implementados em organizações. Cabe ressaltar que estatisticamente em 2011 eram 20 empresas e atualmente são 16 organizações certificadas e auditadas, de acordo com Instituto Nacional de Metrologia, Normalização e Qualidade Industrial (INMETRO, 2020).

As normas orientam para uma política de responsabilidade social. Em essência, a NBR 16001 orienta sobre Sistema de Gestão de Responsabilidade Social e a ISO 26000 diz respeito às Diretrizes sobre Responsabilidade Social. Tanto a NBR16001 quanto a ISO 26000 se propõem ser aplicável a todos os tipos de organizações, independentemente se for uma escola, uma ONG, uma indústria, um hospital, um asilo ou qualquer tipo de negócio. Elas se aplicam à organizações de qualquer porte, independentemente se corresponder às escalas de micro, pequena, média ou grandes empresas. Da mesma forma, as normas acolhem os empreendimentos em qualquer território, onde quer que eles estejam localizados.

A proposta da NBR 16001 é apresentar os procedimentos que devem ser conduzidos dentro de um sistema da gestão, de maneira que esteja estruturado e possa ser integrado à organização. Por sistema de gestão de responsabilidade, a "ANBT NBR 16001 - 2004 Sistema de Gestão de Responsabilidade Social - Requisitos" (2004, p.03) define como sendo um "conjunto de elementos inter-relacionados ou interativos, voltados para estabelecer políticas e objetivos da responsabilidade social, bem como para atingi-los". Considerando-se como premissa que o "sucesso do sistema depende do comprometimento de todos os níveis e funções, especialmente da Alta Administração".

Após chegarem num consenso, os membros participantes da ISO consolidaram que o comprometimento das organizações se faz, essencialmente, muito mais importante para prática e disseminação da responsabilidade do que rótulos ou marcas de cunho publicitário (Cajazeira e Barbieri, 2006). Devido aos aspectos de diferenciação entre etnias, cabe a própria organização definir sua gestão estratégica e as operações da empresa respeitando uma série de princípios orientados pela norma ISO 26000. 
De acordo com Cultri et. al (2010), cada organização é estimulada a se tornar mais socialmente responsável ao usar a Norma Internacional ISO 26000 e Norma Brasileira ABNT NBR 16001 como referências na gestão. Reconhecendo que as organizações se encontram em diferentes estágios de entendimento e integração da responsabilidade social, essa norma foi concebida para ser utilizada tanto pela organização que começa a abordar o tema da responsabilidade social como aquela mais experiente em sua implementação.

É um diferencial da ISO 26000 fazer referência as normas de qualidade em gestão e respeito ao consumidor, orientando-se a partir dos acordos da Organização Mundial do Comércio (OMC). Inclui-se entre os diferenciais dessa norma, a perspectiva de ciclo de vida e algumas preocupações com temas de efeitos globais, como por exemplo: segurança alimentar, tecnologia da informação, requisitos de bem-estar animal, às necessidades das pessoas idosas e pessoas com deficiência, entre outras.

A norma da ABNT traz um alinhamento junto a cinco relevantes documentos internacionais e um documento do Instituto Brasileiro de Governança Corporativa (IBGC) intitulado de "Código das Melhores Práticas de Governança Corporativa". No que tange a documentos internacionais a ISO 26000 traz uma série com 137 referências, sobre temas diversos abrangendo desde o respeito para com os seres humanos, representados na figura dos idosos e crianças, assim como, preservação de animais e de recursos naturais do planeta. Isto representa a legitimidade destas normas junto a outras comunidades e denota a relevância social em várias de suas dimensões.

Por todas estas questões, se observa que a ISO 26000 fornece orientações sobre os princípios subjacentes à responsabilidade social indicando adaptabilidade para cada região. Ela não anula e nem tira a importância de outras normas, ela sugere principalmente o alinhamento com documentos que tragam orientações para adaptação a cultura local.

\subsection{O desenvolvimento local e seus desdobramentos}

Os valores envolvidos no Desenvolvimento Local (DL) centralizam aspectos sociais, ao mesmo tempo em que reforça as relações de confiança entre os atores e manifesta-se considerando os diversos interesses entre os agentes locais. De acordo com Joyal (2004), mais do que uma abordagem de organização comunitária é um conceito onde a comunidade se define e identifica os problemas que ela quer abordar, desenvolver soluções coletivas, apresentar e estabelecer as ferramentas necessárias para alcançá-las.

Rossini e Martinelli (2007) reportam que o Desenvolvimento Local deve levar em consideração uma visão sistêmica de desenvolvimento. Joyal et. al. (2004) definem o desenvolvimento local como qualquer processo de mobilização dos agentes locais com base em uma lógica territorial em oposição a racionalidade estritamente econômica. Para os autores, um processo de desenvolvimento local é caracterizado pelo valor das iniciativas locais voluntárias para se facilitar o acesso dos agentes locais aos recursos estratégicos, tais como: conhecimento tecnológico, recursos humanos qualificados, serviços diversificados e financiamento para o desenvolvimento local, assim como ações em prol de maximizar as externalidades positivas e facilitar sinergias entre as redes de atores. 
Trazendo o desenvolvimento local para o âmbito da sustentabilidade, Frey (2003) apresentou seu trabalho sobre o desenvolvimento sustentável local. Nesse contexto, a sociedade em rede foi investigada sob a perspectiva das comunidades enquanto possíveis agentes de transformação. Isto denota a relevância de se observar o papel da sociedade em atuar responsavelmente, o que caracteriza o conceito de capital social dentro da abordagem de DL.

A partir da publicação do livro Making Democracy Work, de Robert Putnam, em 1993, destacou-se a concepção sobre 'capital social', referindo-se a eles, como sendo "elementos de organização social como as redes, normas e confiança social que facilitam a coordenação e a cooperação em benefício recíproco" (Putnam, 1993, p. 67). Como parte do capital social de uma localidade, pode-se observar o exercício e a construção de valores das empresas, organizações governamentais e não-governamentais, associações, partidos políticos, escolas, grupos religiosos, sindicatos, organizações cívicas, organizações fraternais, entre outras.

A questão da sustentabilidade participa da construção do espaço de "qualidade de vida" e a noção de desenvolvimento sustentável perpassa no DL a partir concepção do DLIS Desenvolvimento Local Integrado e Sustentável. Augusto de Franco (1999) apud Projeto Engenho de Sonhos (2019) apresenta o DLIS como resultado de um amplo debate entre organizações não governamentais, de governo e organismos internacionais:

Desenvolvimento local integrado e sustentável é um novo modo de promover o desenvolvimento que possibilita o surgimento de comunidades mais sustentáveis, capazes de suprir suas necessidades imediatas, descobrir ou despertar suas vocações locais e desenvolver suas potencialidades específicas além de fomentar o intercâmbio externo, aproveitando-se de suas vantagens locais (FRANCO, 1999, p. 55).

Neste sentido, entende-se que o desenvolvimento local é demarcado pela identidade de uma comunidade em relação às atividades que ela desempenha e sobrevive socioeconomicamente. Podendo ser sustentavelmente de baixo impacto social e ambiental.

\section{METODOLOGIA}

No contexto atual em que percebemos através das demandas da sociedade a necessidade de políticas brasileiras e internacionais com direcionamentos que assegurem o desenvolvimento local, fizemos um levantamento da literatura para explorar uma possível relação entre responsabilidade social e desenvolvimento local. O objetivo foi realizar um estudo bibliográfico e analisar sobre a ótica do estudo de caso, como tem sido abordado o assunto "Responsabilidade Social" no âmbito local do Arranjo Produtivo Local de Equipamentos Médicos Hospitalares e Odontológicos de Ribeirão Preto - SP.

O constructo teórico seguiu duas principais etapas, uma relativa à revisão bibliográfica e outra de estudo de caso baseada em Gil (2009) com técnicas de pesquisa exploratória. Foram realizados uma breve revisão de literatura sobre o tema nas bases de dados: SCIELO, Google Scholar e no ambiente virtual AVAdmin/UFSCar com os temas sobre a "Responsabilidade Social" e "Desenvolvimento Local". 
Para enriquecer os nossos questionamentos e argumentos, realizamos um levantamento buscando sites das empresas e organizações com alto impacto na localidade de Ribeirão Preto, tais como Serviço Brasileiro de Apoio às Micros e Pequenas Empresas (SEBRAE), Supera Incubadora Unidade Campus USP (SUPERA), Fundação Instituto Pólo Avançado da Saúde (FIPASE), prefeitura entre outras que compõem o Arranjo Produtivo Local de Equipamentos Médicos e Hospitalares de Ribeirão Preto - SP. Visto sua relevância de grande impacto local e internacional no que tange a área de tecnologia e saúde.

Em nossa breve revisão e análise da literatura a respeito da temática "Responsabilidade Social" e suas características, destacamos autores envolvidos com a temática há décadas: Tachizawa (2002), Ashley (2003), Cajazeira e Barbieri (2006), Singer (2002) e Cultri; Saavedra e Ometto (2010). Além destes, instituições de alta relevância como International Standart Organization (ISO), United Nations Environment Programme (UNEP), Instituto Nacional de Metrologia, Normalização e Qualidade Industrial (INMETRO), Associação Brasileira de Normas Técnicas (ABNT) e Instituto ETHOS de responsabilidade social. Para contextualizar as noções de "Desenvolvimento Local" destaque para experiência de Silveira e Bocayuva (1999), Frey (2003), Joyal (2004), Rossini e Martinelli (2007) e Aguilera Urquiza e Maciel (2019).

\section{RESULTADOS E DISCUSSÕES}

Nesta sessão duas abordagens serão apresentadas como sendo resultados dos caminhos pelo qual se percorreu neste estudo. A primeira delas relacionou a Responsabilidade Social e Desenvolvimento Local e a segunda, apresentará as características e evidências do Arranjo Produtivo Local de Equipamentos Médicos Hospitalares e Odontológicos de Ribeirão Preto - SP.

\subsection{Relacionando Responsabilidade Social e Desenvolvimento Local}

No contexto geral da sociedade brasileira é possível perceber a necessidade por políticas que assegurem o desenvolvimento de cada local, dada extensa variedade do nosso território. Neste sentido, apresentamos com base na literatura um quadro com algumas possíveis relações entre responsabilidade social e desenvolvimento local. A análise partiu da relação entre os temas sociais internacionalmente consagrados na norma de Responsabilidade Social ISO 26000 (2010) e os assuntos abrangidos pela literatura de desenvolvimento local, ver Tabela 01.

Tabela 1 - Componentes congruentes entre a norma ISO 26000 Responsabilidade Social com os objetos de estudo do Desenvolvimento Local

\begin{tabular}{|c|c|c|c|c|c|c|c|}
\hline $\begin{array}{l}\text { Desenvolvimento Local/ } \\
\text { ISO 26000:2010 }\end{array}$ & 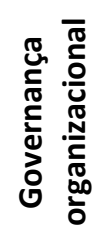 & 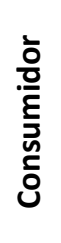 & 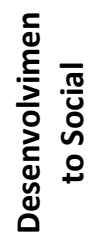 & 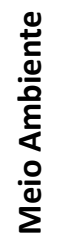 & 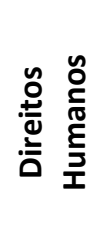 & 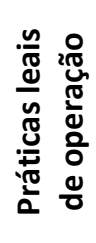 & 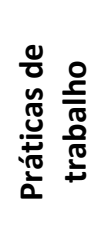 \\
\hline Processo reativador da economia & $x$ & & & & & & \\
\hline Dinamização da sociedade local & & $\mathrm{X}$ & $x$ & & & & \\
\hline
\end{tabular}




\begin{tabular}{|c|c|c|c|c|c|c|}
\hline $\begin{array}{l}\text { Aproveitamento eficiente dos recursos } \\
\text { endógenos }\end{array}$ & & $\mathrm{x}$ & $\mathrm{x}$ & & $\mathrm{x}$ & \\
\hline Estimular crescimento econômico & $\mathrm{X}$ & & & & & \\
\hline Criação de empregos & $x$ & & & & & \\
\hline Qualidade de vida & & $x$ & $\mathrm{X}$ & $x$ & & \\
\hline Participação dos gestores públicos e privados & & $\mathrm{X}$ & & $x$ & & \\
\hline Capacitação da força de trabalho local & & $\mathrm{X}$ & & & $\mathrm{X}$ & $\mathrm{X}$ \\
\hline Ações de cooperação & $x$ & $\mathrm{X}$ & & & $\mathrm{x}$ & $\mathrm{x}$ \\
\hline DLIS & & $x$ & $\mathrm{X}$ & & & \\
\hline Abordagem Sistêmica & & $\mathrm{X}$ & & & & \\
\hline Perspectiva de inovação & $\mathrm{X}$ & & & & & \\
\hline Economia Solidária (SINGER, 2002) & & $\mathrm{X}$ & & & & \\
\hline Network & $\mathrm{X}$ & & & & $x$ & \\
\hline Capital social & & $x$ & & $x$ & & $x$ \\
\hline
\end{tabular}

Observa-se que o processo de governança organizacional praticado pelas empresas tem relação direta com o $\mathrm{DL}$, principalmente analisando o potencial das organizações em reativar a economia local através dos estímulos para o crescimento econômico e sustentável de cada localidade. O princípio de Desenvolvimento Social referenciado pela ISO mantém estreita relação com a participação dos gestores públicos e privados, ações de cooperação, dinamização da comunidade e aspectos da qualidade de vida. Resgatando os incentivos da ISO para o Desenvolvimento Social, fica respaldado que a responsabilidade se dissemina através de comando, conduta justa, ética e transparência de modo que a responsabilidade autodeclarada por uma empresa reflita sua efetividade prática e os efeitos da sua corroboração com a comunidade.

O respeito aos direitos humanos e a orientação da norma para as práticas leais de operação envolvem questões de saúde e segurança, mas também incorporam respeito aos grupos vulneráveis, à criação de emprego, proteção social, uso sustentável da terra, conservação e restauração de ecossistemas e natureza, bem como o incentivo aos produtos ambientalmente e socialmente benéficos.

Atualmente, a temática ambiental tem reforço na mídia e sua repercussão encontra apoio para ser disseminada no DL. Desse modo, encontra-se relação no que tange ao aproveitamento eficiente dos recursos endógenos e fatores ambientais que asseguram a qualidade de vida. Além da participação do DLIS que intrinsecamente propaga o valor ambiental.

Na responsabilidade social, as questões abordadas pelo grupo de práticas leais de operação incentivam aspectos éticos e transparentes, promoção dos stakeholders desfavorecidos, respeito pelos direitos de propriedade, envolvimento comunitário e a contribuição para desenvolvimento econômico. Isso pode estar relacionado com a política de network apoiada pelo DL, além das ações de cooperação. E com relação ao grupo das práticas de trabalho, os focos analisados são nos direitos do trabalhador e no diálogo social. Enquanto que no DL estas questões são reforçadas através da capacitação da força de trabalho local e pelo especial tratamento dispensado ao capital social. 


\subsection{O Arranjo Produtivo Local de Equipamentos Médicos Hospitalares e Odontológicos de Ribeirão Preto - SP}

Uma nova economia baseada na fabricação de equipamentos para hospitais e consultórios odontológicos está consolidando o Arranjo Produtivo Local cidade de Ribeirão Preto, localizada no interior do Estado de São Paulo. A excelência nos serviços da área da saúde fez com que a cidade se tornasse reconhecida e com isso, passasse a oferecer uma ampla diversidade de inovações em produtos e serviços.

Optou-se denominar de atores sociais aqueles que impulsionaram decisivamente o Desenvolvimento Local. Para ilustrar os atores locais, relativamente mais atuantes no APL EMHO de Ribeirão Preto apresentamos a Figura 1.

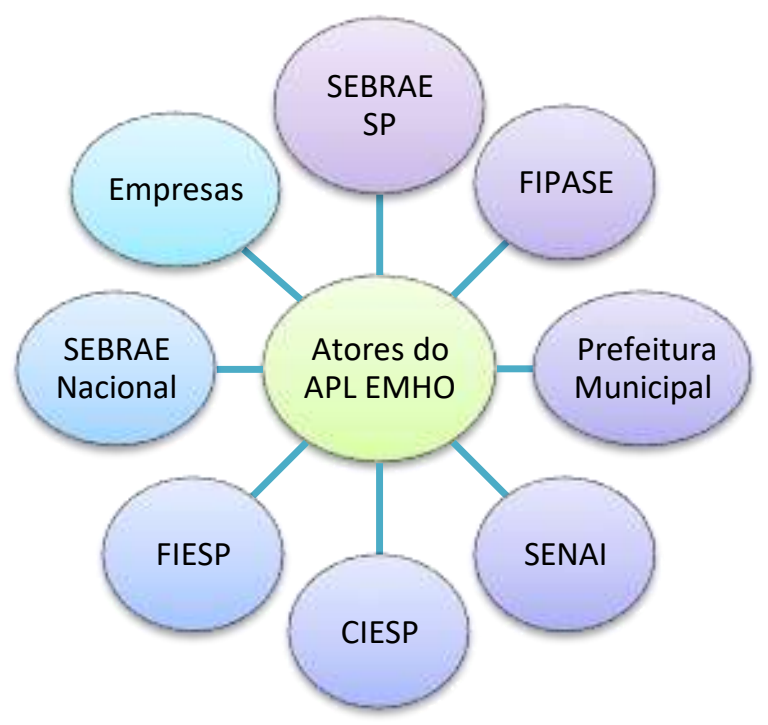

Figura 1 - Representação dos atores do desenvolvimento local do APL EHMO Fonte: Microem Produtos Médicos Ltda. (2019)

Fatos marcantes ocorreram em 2003, quando foi instalado a Supera Incubadora - Unidade Campus USP com a missão de gerenciar o Parque Tecnológico. Logo, em 2005 consolidou-se o APL da Saúde e, mais adiante, o APL de Software foi conectado. E com isto se foram transferindo tecnologias que trouxeram várias premiações para a entidade. Em 2019, a Supera Incubadora foi premiada pela UBI Global como uma das 20 melhores Incubadoras Universitárias de Negócios do Mundo.

Em termos de características sobre a cidade de Ribeirão Preto, segundo dados da Relação Anual de Informações Sociais - RAIS (2005) apud Microem (2019), atualmente encontram-se 53 empresas do setor de equipamentos médicos, hospitalares e odontológicos. A maioria das empresas são compostas por micro (com até 9 empregados), pequenas (até 19 empregados) e médias empresas (de 10 a 49 empregados). Juntas essas empresas empregam mais de 1.300 pessoas e fazem da cidade referência em produção e tecnologia para o setor de saúde.

A região de Ribeirão Preto conta boa infraestrutura para agenda de negócios, incluindo hospedagens e meios logísticos. De modo facilitado, nesta região estão hospedados fornecedores 
de peças e componentes, fábricas de equipamentos médicos, distribuidores, universidades, centros de pesquisa e vários hospitais e centros de saúde.

Analisando o contexto local e os indicadores sociais, pode-se perceber que em geral as ações encontradas no APL, as quais, foram divulgadas nas mídias ou nas literaturas analisadas não postulam com veemência os princípios da Responsabilidade Social dos atores locais. Dificultandose, assim, perceber as ações sociais do APL EHMO. Entretanto, algumas questões das entidades locais devem ser reconhecidas por demonstrar os estágios das realizações no APL. Deste modo, apresenta-se pontos de partida para incentivo da Responsabilidade Social via Desenvolvimento Local em Ribeirão Preto.

A Fundação Instituto Pólo Avançado da Saúde (FIPASE) foi constituída pela Lei Complementar n. 1222 de 30 de maio de 2001 e alterada pela Lei Complementar n. 2291, de julho de 2008. Classifica-se como um ente público de direito privado, cujo propósito é promover o desenvolvimento socioeconômico local e regional, com base na pesquisa e aplicação do conhecimento cientifico e tecnológico. Para efeitos legais, ela é uma Instituição Científica e Tecnológica (ICT), com Núcleo de Inovação Tecnológica (NIT) com finalidade de gerir políticas de inovação (FIPASE, 2019). Nesta pesquisa, esta organização foi consultada por ser uma representante do setor, a qual tem amplo conhecimento sobre as estratégias empresariais.

Um dos projetos da FIPASE é a SUPERA - Incubadora de Empresas de Base Tecnológica que opera desde 2003. Para tanto, é uma organização sem fins lucrativos, a qual visa oferece apoio para a criação de novos negócios. No seu portfólio ela oferece espaço físico para o empreendimento, serviços básicos, assessoria, capacitação e networking. Observa-se que a inovação tecnológica é a base desse negócio, cujo objetivo da SUPERA é contribuir para a criação, desenvolvimento e aprimoramento de micro e pequenas empresas de base tecnológica nos seus aspectos tecnológicos, gerenciais, mercadológicos e de recursos humanos.

O caráter social pode ser reconhecido apenas nas aclarações acerca da criação de novas oportunidades de trabalho e a melhoria de desempenho dos negócios, isto inclui treinamento e indicação de cursos aos funcionários. Por tratar de um ramo de alta tecnologia, muitas vezes as condições de trabalho das empresas incubadas não são percebidas como críticas, dado que vários funcionários são pesquisadores ou ex-alunos da área de saúde e tecnologia que se tornam empreendedores do próprio trabalho. A SUPERA mantém incubadas empresas que desenvolvam produtos com alta densidade tecnológica, nas áreas de biotecnologia, materiais e equipamentos médicos-odontológicos, tecnologia da informação, química, e técnicas nucleares, entre outros e por isso todas as adequações físicas requeridas pela ANVISA são respeitadas no ambiente das empresas.

Do lado empresarial, observa-se a atenção dos empresários nas feiras e eventos principalmente porque se trata de produtos de alta tecnologia, os quais demandam acompanhamentos das tendências do mercado. Para regulamentação dos equipamentos EMHO, as empresas devem atender os códigos do setor auditado pela ANVISA - Agência Nacional de Vigilância Sanitária, que certifica as empresas com o BPF - Boas Práticas de Fabricação. Além deste certificado, as empresas se orientam para padrões de qualidade visando atender requisitos dos clientes. 
Em busca de identificar ações dos empresários locais, foi realizada uma visita a empresa (aqui denominada de A), cuja principal atividade é Pesquisa e Desenvolvimento. Ela é uma empresa de sociedade empresária limitada que conta apenas com os dois sócio-proprietários e um funcionário. Ela fornece a seus clientes e parceiros a realização de projetos de equipamentos eletrônicos para a medicina, com consultoria e treinamento nas áreas de instrumentação médica e ultrassom tendo como principal meta criar e desenvolver produtos inovadores na área médica hospitalar.

A empresa A tem como missão gerar e transferir inovação, conhecimento e tecnologia para o mercado e fazer que isso seja acessível para a sociedade. Observa-se que esta empresa utiliza investimentos públicos por participar de editais e financiamentos. Esta situação instigou o fato de verificar se há algum tipo de requisito nos editais públicos com relação à responsabilidade social da empresa. Após as análises dos editais e a confirmação com um dos empresários, não se localizou nenhum tipo de requisito de gestão de Responsabilidade Social no âmbito dos editais. Uma vez que estes, enquanto instrumentos das políticas públicas, poderiam fazer alguma exigência para as empresas que acessam investimentos públicos.

Com relação à prefeitura da cidade de Ribeirão Preto foram investigadas algumas ações que configuram sinergia com o APL, bem como a recomendação e cobrança pela responsabilidade social das empresas. Em termos de documentos não são exigidos nenhum outro compromisso, além das questões legais para abertura das empresas. A relação da prefeitura com os atores locais demonstram assuntos de interesse geral, no qual os dirigentes públicos inferem para melhoria das condições da comunidade.

O SEBRAE - Serviço Brasileiro de Apoio às Micros e Pequenas Empresas se destaca como um relevante apoiador de ações em prol do APL. Este órgão analisa a concorrência e impulsiona para a denominada de Estratégia do Cuidado Contínuo em Saúde, a qual prevê que as pessoas tendem cada vez mais a ficar com doenças crônicas e, por isso, precisarão de equipamentos domésticos para controlar suas doenças no seu próprio ambiente conhecido como "home-care" (cuidados domiciliares). Entre estes equipamentos destacam-se medidores de pressão arterial, medidores de diabetes, móveis e camas adaptados a cada tipo de disfunção.

O desenvolvimento desses produtos requer a integração da cadeia de valor com novos atores do ramo de Inovação Tecnológica, além dos agentes de saúde que farão o aconselhamento às pessoas, operando dentro do sistema de "cuidado contínuo". Esse sistema tem como característica o monitoramento constante da saúde de cada pessoa, que inclui prevenção, aconselhamento em saúde e tratamento, de forma a prever as doenças e poder tratá-las à distância. Por essa razão, o SEBRAE incentiva quatro linhas de ação, consideradas como estratégicas para o desenvolvimento atual e futuro do pólo. As linhas de ação são:

1. Integração: estabelecer canais de contato entre os atores da cadeia de valor da saúde, principalmente entre a demanda e os fabricantes de equipamentos, fazendo com que esse processo de inovação seja contínuo e integrado.

2. Formação: ofertar de cursos relacionados à nova estratégia para os empresários e agentes interessados nessa oportunidade, desde informações sobre potenciais mercados / oportunidades até 
desenvolvimento de produtos e realização de parceiras estratégicas no segmento de tratamento contínuo.

3. Desenvolvimento de Projetos: proporcionar suporte para a elaboração e desenvolvimento de projetos relacionados ao segmento de cuidado contínuo.

4. Sensibilização: desenvolver ação relacionada com a formação e sensibilização da demanda e canalização de recursos para o financiamento de projetos (SEBRAE, 2011).

Embora, o setor venha despontando como relevante pólo produtor de EMHO para a economia local e para a economia brasileira, ele vem sofrendo muita influência da concorrência. Este fato torna evidente alguns desafios que acaba culminando no enfraquecimento das empresas locais. Sobre estas causas, o SEBRAE diagnosticou alguns pontos que vem sendo abordado no planejamento estratégico para orientação das empresas do setor:

- Baixa inovação das empresas

- Estratégia baseada em preço

- Pouca integração entre os agentes da cadeia de valor

- Produtos maduros em seu ciclo de vida

- Desafios advindos dos concorrentes, principalmente dos chineses (SEBRAE, 2011)

De modo geral, o SEBRAE como organizador deste comitê realiza o planejamento estratégico para o setor e aplica alguns indicadores para monitoramento de desempenho. Contudo, os indicadores utilizados são puramente financeiros, tais como o faturamento das empresas e a diminuição de custos. Isto sintetiza que o valor social não está presente, como poderia estar, nas estratégias atuais e no planejamento do setor. A questão em foco remete a sobrevivência do setor considerando-se fatores críticos a concorrência e a dificuldade de desenvolver o produto com preços competitivos.

Em linhas gerais, a Responsabilidade Social divulgada pelos atores do APL EHMO recai principalmente nos padrões de segurança, que obrigam os funcionários usar equipamentos de proteção individual (EPI) tais como luvas, óculos e protetores de ouvidos. Outro destaque apontando é o silêncio no ambiente de trabalho pela aquisição de máquinas e equipamentos antirruídos (SEBRAE, 2011).

\section{CONSIDERAÇÕES FINAIS}

Os temas sociais mais populares referentes às carências e necessidades sociais de diversos países, ainda não é fácil de ser identificado como preocupação local em Ribeirão Preto - SP. Em suma, as organizações pesquisadas SEBRAE, PREFEITURA, FIPASE, SUPERA e uma empresa de micro porte sediada na incubadora do campus da Universidade de São Paulo (campus USP de Ribeirão Preto) reforçam a necessidade de ganho financeiro e de posicionamento no mercado, enquanto estratégias essenciais ao setor.

Um fator positivo observado durante o discurso dos atores ressaltou que os atores locais demonstram interesse acerca do fomento às cooperativas e instituição de cursos de formação e de 
qualificação profissional, todavia as compras coletivas e o incentivo aos funcionários ocorrem como estratégia para reduzir os custos individuais das empresas.

O portfólio de responsabilidade social é amplo e fomenta ações para diversos campos de atuação. As recomendações da Agência Nacional de Vigilância Sanitária (ANVISA) sobre "Boas Práticas de Fabricação" já se configuram em orientações que podem ser trabalhadas juntamente com os indicadores sociais. Utilizando as normas ABNT NBR 16001 e ISO 26000 como referência, pode melhorar o desempenho das organizações para administrarem seus negócios nos mercados mais exigentes de produtos sustentáveis. De maneira que a RS possa elucidar mais valor do produto, considerando, por exemplo, o capital social.

Com o uso de ferramentas de gestão e de indicadores sociais das normas analisadas, as empresas podem fazer uso para apresentarem seus resultados, melhorando assim o desempenho organizacional perante a comunidade. Algumas ferramentas extraídas das normas e da literatura que podem ser utilizadas pelas empresas do APL, são: Indicadores Ethos, Guia de Elaboração de Balanço Social, Matriz de Evidências de Sustentabilidade, Banco de dados do Instituto Ethos, Guia de Balanço Social do Instituto Brasileiro de Análises Socioeconômicas, Diretrizes para Relatórios de Sustentabilidade da Global Report Initiative (GRI) e diretrizes da Organização das Nações Unidas (ONU).

Desta forma, sugere-se a inclusão dos indicadores sociais no planejamento do setor e das empresas, bem como a utilização de ferramentas que possam demonstrar a evolução do APL com vistas a incorporar práticas de sustentabilidade. Facilitando o modo como poderão ganhar novos mercados, ser referência no modelo de gestão e contribuir para um Desenvolvimento Local mais solidário e articulado. Sobretudo respeitando a dinâmica coletiva das pessoas e dos funcionários que vivem na região do APL EMHO. Atualmente, esta região também agrega o APL de Software e o Centro de Capacitação Profissional em Software. De modo, que todas estas organizações estão instaladas no Parque de Inovação e Tecnologia de Ribeirão Preto denominado de "Parque Supera".

Findamos a nossa reflexão no desejo de termos cumprido a inspiração de demonstrar a importância das relações entre o campo da responsabilidade social e o desenvolvimento local especialmente no sentido de tornar este estudo de caso uma oportunidade para pessoas interessadas poderem compreender a realidade de um Arranjo Produtivo Local, localizado em uma cidade de médio porte no Estado de São Paulo. Com nossa experiência nesta região, pudemos caracterizar o ambiente alta tecnologia e de especialização, composto por profissionais especializados no segmento médico, hospitalar e odontológico. Por fim, registramos a necessidade de reflexões mais aprofundadas sobre esses temas e, principalmente, novos estudos que apontem os seus desempenhos.

\section{AGRADECIMENTOS}

Este estudo teve apoio parcial da Coordenação de Aperfeiçoamento de Pessoal de Nível Superior (CAPES). Por este motivo agradecemos ao Ministério da Educação por financiar o ensino, a pesquisa e a extensão em universidades públicas do Brasil. 


\section{REFERÊNCIAS}

Ashley, P. A. et al. (2003). Ética e responsabilidade social nos negócios. São Paulo: Saraiva.

Associação Brasileira de Normas Técnicas. (2019). ANBT NBR 16001 - Sistema de Gestão de Responsabilidade Social - Requisitos. Disponível em: <http://www.abnt.org.br >. Acesso: 18 jun 2019.

Barbosa, A. D. S. (2004). Empresário fabril e desenvolvimento econômico: empreendedores, ideologia e capital na indústria do calçado: Franca, 1920-1990. 2004. 285 f Tese (Doutorado em Sociologia) Faculdade de Ciências e Letras, Universidade Estadual Paulista, Araraquara).

Brundtland, G.H. (1987). Our Common future. Nairobi: UNEP.

Cajazeira, J., \& Barbieri, J. (2006). ISO 26000-a quem interessa a norma internacional de responsabilidade social. Anais IX Simpósio de Administração da Produção, Logística e Operações Internacionais, São Paulo.

Correia, R. L., Costa, S. L. D., \& Akerman, M. (2017). Processos de ensinagem em desenvolvimento local participativo. Interações (Campo Grande), 18(3), 23-29.

Cultri, C. N., Barrera Saavedra, Y. M., \& Ometto, A. R. (2010). Indicadores sociais como subsídios para a avaliação social do ciclo de vida: uma revisão de literatura. Anais.

Fórum engenho de sonhos de combate à pobreza. (2019). Projeto Engenho de Sonhos. [s.d.]. Disponível em: <http://www.ufrn.br/sites/engenhodesonhos/hipertexto/delis.htm>. Acesso: 01 jul 2019.

Francisco, W. C. (2020). População da França; Brasil Escola. Disponível em: <https://brasilescola.uol.com.br/geografia/franca2.htm>. Acesso: 02 abr 2020.

Franco, A. (1999). Desenvolvimento Local Integrado. São Paulo: Cortês.

Frey, K. (2003). Desenvolvimento sustentável local na sociedade em rede: o potencial das novas tecnologias de informação e comunicação. Revista de Sociologia e Política, (21), 165-185.

Fundação Instituto Pólo Avançado da Saúde (FIPASE). (2019). SUPERA Parque. [s.d.]. Disponível em: <http://www.fipase.org.br>. Acesso: 06 jun 2019.

GIL, A. C. 2009. Estudo de caso. São Paulo, Atlas, 2009.

Instituto Nacional de Metrologia, Normalização e Qualidade Industrial (INMETRO). (2020). Responsabilidade Social. INMETRO, [s.d.]. Disponível em: Disponível: <http://www.inmetro.gov.br/qualidade/responsabilidade_social/>. Acesso: 13 jan 2020.

International Standart Organization (ISO). (2019). ISO 26000 - Guidance on social responsibility. ISO, [s.d.]. Disponível em: Disponível em: <http://isotc.iso.org/livelink/ >. Acesso em: 10 dez 2019. 
Joyal, A. (2004). Les entreprises alternatives dans le développement local. Canadian Journal of Regional Science. Revue canadienne des sciences régionales, 12(1), 75-91.

Microem Produtos Médicos Ltda. Apresentação. [s.d.]. Disponível em: <http://www.microem.com.br/principal/index.php>. Acesso em: 12 dez 2019.

Putnam, R. (1993). Making Democracy Work. Civic Traditions in Modern Italy. Princeton: NJ, Princeton University Press.

Rodrigues, W. \& Santos, N. S. (2018). Desenvolvimento territorial no Brasil: uma análise a partir da concepção teórica de Karl Polanyi. Interações (Campo Grande), 19(1), 119-135.

Rossini, V. \& Martinelli, D. (2007). Visão Sistêmica e Desenvolvimento Local: um estudo multicasos em uma cidade de pequeno porte no interior de São Paulo. Anais.

Serviço Brasileiro de Apoio às Micros e Pequenas Empresas. (2011). Inova Saúde Ribeirão Preto. São Paulo: SEBRAE.

Silveira, c. M., \& Bocayuva, P. C. C. (2001). Desenvolvimento local integrado e sustentável: enfoque estratégico e construção de indicadores. Revista Interface, (1).

Singer, P. (2002). A recente ressurreição da economia solidária no Brasil. Produzir para viver: os caminhos da produção não capitalista. Rio de Janeiro: Civilização Brasileira, 2.

Supera Parque de Inovação e Tecnologia de Ribeirão Preto. Apresentação. [s.d.]. Disponível em: $<w w w$.fipase.org.br>. Acesso: 06 set 2019.

Tachizawa, T. (2002). Gestão Ambiental e Responsabilidade Social Corporativa: estratégias de negócios focadas na realidade brasileira. São Paulo: Atlas.

Urquiza, Antonio Hilário Aguilera, \& Maciel, Josemar de Campos. (2019). Desenvolvimento Local e a expansão de empresas multinacionais. Discussão a partir de dois municípios de Mato Grosso do Sul, Brasil. Interações (Campo Grande), 20(4), 1217-1233. Epub December 05, 2019.https://doi.org/10.20435/inter.v0i0.1988. 